review and exploratory meta-analysis. J Infect Dis. 2015; 211:80-90. http://dx.doi.org/10.1093/infdis/jiu396

6. Zhou B, Zhong N, Guan Y. Treatment with convalescent plasma for influenza A (H5N1) infection. N Engl J Med. 2007;357:1450-1. http://dx.doi.org/10.1056/NEJMc070359

7. van Griensven J, Edwards T, de Lamballerie X, Semple MG, Gallian P, Baize S, et al. Evaluation of convalescent plasma for Ebola virus disease in Guinea. N Engl J Med. 2016;374:33-42. http://dx.doi.org/10.1056/NEJMoa1511812

8. Shimada S, Posadas-Herrera G, Aoki K, Morita K, Hayasaka D. Therapeutic effect of post-exposure treatment with antiserum on severe fever with thrombocytopenia syndrome (SFTS) in a mouse model of SFTS virus infection. Virology. 2015;482:19-27. http://dx.doi.org/10.1016/j.virol.2015.03.010

9. Kim UJ, Kim DM, Ahn JH, Kang SJ, Jang HC, Park KH, et al Successful treatment of rapidly progressing severe fever with thrombocytopenia syndrome with neurological complications using intravenous immunoglobulin and corticosteroid. Antivir Ther. 2016 Feb 17. Epub ahead of print. http://dx.doi.org/10.3851/IMP3036

Address for correspondence: Sung-Han Kim, Department of Infectious Diseases, Asan Medical Center, University of Ulsan College of Medicine, 86 Asanbyeongwon-Gil, Songpa-Gu, Seoul, 138-736, Republic of Korea; email: kimsunghanmd@hotmail.com

\section{Naturally Circulating Hepatitis A Virus in Olive Baboons, Uganda}

\author{
Andrew J. Bennett, Samuel D. Sibley, \\ Michael Lauck, Geoffrey Weny, David Hyeroba, \\ Alex Tumukunde, Thomas C. Friedrich, \\ David H. O'Connor, Caley A. Johnson, \\ Jessica M. Rothman, Tony L. Goldberg
}

Author affiliations: University of Wisconsin, Madison, Wisconsin, USA (A.J. Bennett, S.D. Sibley, T.L. Goldberg); Wisconsin National Primate Research Center, Madison (M. Lauck, T.C. Friedrich, D.H. O'Connor, T.L. Goldberg); Makerere University, Kampala, Uganda (G. Weny, D. Hyeroba, A. Tumukunde, J.M. Rothman, T.L. Goldberg); Graduate Center of City University of New York, New York, New York, USA (C.A. Johnson, J.M. Rothman); New York Consortium in Evolutionary Primatology, New York (C.A. Johnson, J.M. Rothman); Hunter College of the City University of New York, New York (J. Rothman).

DOI: http://dx.doi.org/10.3201/eid2207.151837

To the Editor: Hepatitis A (HAV; family Picornaviridae; genus Hepatovirus) is an $\approx 7.5$-kb single-stranded positive-sense RNA virus that causes acute inflammation of the liver in humans and nonhuman primates. Although HAV is most commonly transmitted by food and water contaminated with feces, humans have acquired HAV from handling infected nonhuman primates in captivity (1).
HAV has been detected in recently imported captive primates after spontaneous outbreaks of acute hepatitis in animal facilities, but the definitive hosts of this virus have remained obscure $(2,3)$. We identified by next-generation sequencing HAV in the blood of a free-living olive baboon (Papio anubis) from Kibale National Park, Uganda, sampled in September 2010. Subsequent testing of a separate Kibale olive baboon troop in 2014 indicated the virus was prevalent and shed in feces.

As part of a long-term study of nonhuman primate health and ecology, 23 animals were immobilized and sampled in 2010 as previously described (4). All animal protocols received prior approval from the Uganda National Council for Science and Technology (Kampala, Uganda), the Uganda Wildlife Authority (Kampala, Uganda), and the University of Wisconsin-Madison Animal Care and Use Committee (Madison, WI, USA). All samples were shipped in accordance with international laws under Convention on International Trade in Endangered Species of Wild Fauna and Flora Ugandan permit no. 002290.

During May 2012, we subjected total RNA from $1 \mathrm{~mL}$ of blood plasma of each animal to next-generation sequencing as previously described (4); results showed HAV-like sequences in 1 of 23 baboons. De novo assembly of these reads yielded a nearly complete HAV genome, which we term KibOB-1. KibOB-1 is most similar $(94.2 \%$ nt identity; Figure) to AGM-27, an HAV originally detected in an African green monkey (Chlorocebus aethiops) imported to a Russian primate facility from Kenya (3).

For 11 baboons, we also collected a paired fecal sample, which we analyzed for evidence of viral shedding. Samples were preserved in RNAlater (Ambion Inc., Austin, TX, USA) at $-20^{\circ} \mathrm{C}$, and viral RNA was isolated by using the ZR Soil/Fecal RNA Microprep kit (Zymo Research, Irvine, CA, USA) following manufacturer's protocols. Reverse transcription PCR (RT-PCR) of RNA was primed with random hexamers by using the RNA to cDNA Ecodry Premix (Random Hexamers) (Clontech Laboratories, Inc., Mountain View, CA, USA), and diagnostic PCR was conducted with primers flanking the C-terminal extension of the HAV viral protein (VP) 1 gene $(p X)$ by using the High Fidelity PCR Master Mix-Ecodry Premix (Clontech Laboratories, Inc.). Five of 11 paired fecal samples tested positive for HAV by RT-PCR, indicating a higher prevalence of the virus in feces than in blood.

We then surveyed a second troop of habituated olive baboons at the same field site during February-April 2014 (5). From these baboons, 7 of 19 fecal samples tested positive by RT-PCR. Confirmatory Sanger sequencing of RT-PCR amplicons was successful for 3 of these 7 animals (GenBank accession nos. KT819576-KT819578). Phylogenetic analyses of these sequences demonstrate monophyly and a low degree of interhost variability ( $\geq 94 \% \mathrm{nt}$ identity). 
The risk to humans posed by KibOb-1 remains unknown. Although human infection with HAV genotype $\mathrm{V}$ has not been reported, evidence suggests that HAV variants might be capable of infecting a diversity of primate hosts (6). Although it is not known whether the closely related AGM-27 strain was discovered infecting its natural host, the similarity of KibOB-1 and AGM-27 raises the possibility of a recent host transfer. Major host shifts characterize the evolutionary histories of recently discovered bat and rodent hepatoviruses (7). Host fidelity of KibOB-1 is similarly unknown, but experimental infection of several nonhuman primate species with the similar AGM-27 virus found varying pathogenicity in different species (6). In particular, the AGM-27 caused productive infection in chimpanzees, with stimulation of a broadly reactive HAV immunoglobulin response (6).

Human and simian HAVs are considered a single serotype (6); thus, serosurveillance for HAV in humans might

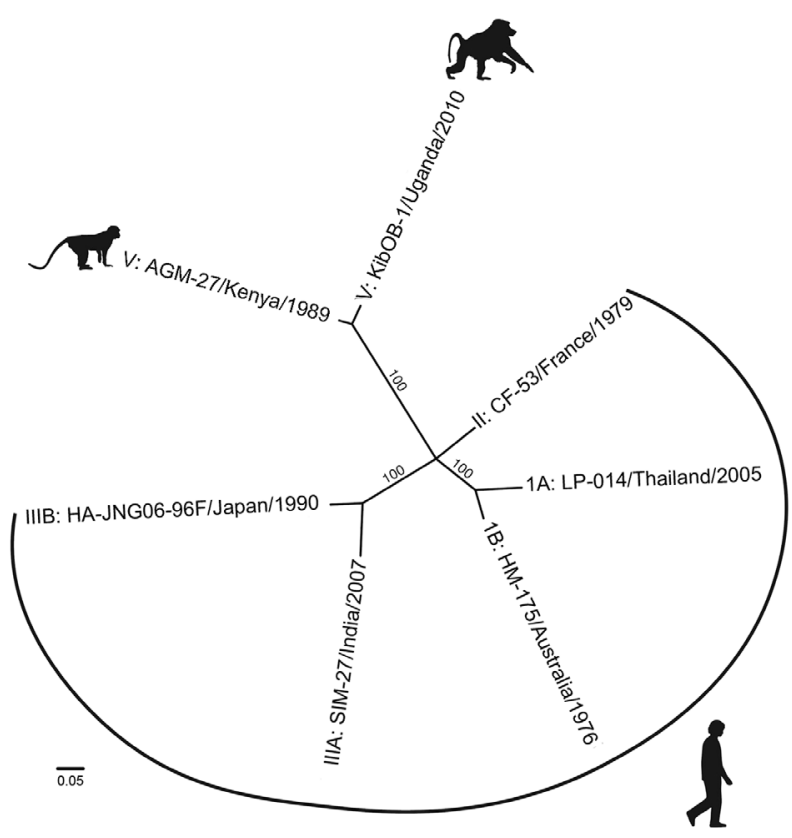

Figure. Whole-genome phylogenetic reconstruction of representative HAVs. HAVs are grouped into 6 genotypes based on $168 \mathrm{bp}$ of the C-terminal extension of the viral protein 1 gene. Baboon HAV detected in Kibale National Park, Uganda, in 2010 and 2014 (GenBank accession number KT819575) clusters with AGM-27 (3), previously the sole member of genotype V. jModeltest 2 (http://jmodeltest.org) was used to find the best-fit evolutionary model for the data, after which the maximum-likelihood tree was estimated using the heuristic search method in PAUP* (http://paup.csit.fsu.edu), with starting trees obtained by neighborjoining, random stepwise addition, and branch swapping by treebisection reconnection and starting branch lengths obtained using Rogers-Swofford approximation. Bootstrap values were derived from 1,000 replicates of the heuristic search; only values $\geq 50 \%$ are shown. GenBank accession nos.: IA, EF207320; IB, M14707; II, AY644676; IIIA, FJ227135; IIIB, AB258387; V, D00924). HAV, hepatitis $A$ virus. Scale bar indicates substitutions per site. be unable to distinguish between human and zoonotic simian HAV infection, enabling the possibility of cryptic zoonotic transmission. Similarly, detection of HAV antibodies in wild primates, such as in a recent study of baboons in South Africa living in close proximity to humans (8), might not indicate anthroponotic transmission of human viruses but rather infection with an endemic HAV.

Prior studies have documented cross-species transmission between the primates of Kibale National Park and neighboring human populations, especially of gastrointestinal pathogens (9). A study tracking food-crop-raiding events on 97 farms within $0.5 \mathrm{~km}$ of Kibale's forest edge found that $72 \%$ of households faced baboon raids over a 23-month period, including 228 discrete baboon raids (10). This finding suggests that a major portion of the local community remains at risk for exposure to potentially infectious baboon excreta. Such exposure, in addition to the evidence presented here that HAV is prevalent in wild baboons of Uganda and is shed into the environment, merits increased attention to the zoonotic risk for simian hepatoviruses.

\section{Acknowledgments}

We gratefully acknowledge the Uganda Wildlife Authority, the Uganda National Council for Science and Technology, Makerere University Biological Field Station, and the staff of the Kibale EcoHealth Project for granting permission to conduct this research.

This work was funded by National Institutes of Health grant TW009237 as part of the joint National Institutes of Health-National Science Foundation Ecology of Infectious Diseases program and the United Kingdom Economic and Social Research Council.

\section{References}

1. Dienstag JL, Davenport FM, McCollum RW, Hennessy AV, Klatskin G, Purcell RH. Nonhuman primate-associated viral hepatitis type A. Serologic evidence of hepatitis A virus infection. JAMA. 1976;236:462-4. http://dx.doi.org/10.1001/ jama.1976.03270050018021

2. Robertson BH, Jansen RW, Khanna B, Totsuka A, Nainan OV, Siegl G, et al. Genetic relatedness of hepatitis A virus strains recovered from different geographical regions. J Gen Virol. 1992;73:1365-77. http://dx.doi.org/10.1099/0022-1317-73-6-1365

3. Tsarev SA, Emerson SU, Balayan MS, Ticehurst J, Purcell RH. Simian hepatitis A virus (HAV) strain AGM-27: comparison of genome structure and growth in cell culture with other HAV strains. J Gen Virol. 1991;72:1677-83. http://dx.doi.org/10.1099/ 0022-1317-72-7-1677

4. Lauck M, Hyeroba D, Tumukunde A, Weny G, Lank SM, Chapman CA, et al. Novel, divergent simian hemorrhagic fever viruses in a wild Ugandan red colobus monkey discovered using direct pyrosequencing. PLoS One. 2011;6:e19056. http://dx.doi.org/10.1371/journal.pone.0019056

5. Johnson CA, Swedell L, Rothman JM. Feeding ecology of olive baboons (Papio anubis) in Kibale National Park, Uganda: preliminary results on diet and food selection. Afr J Ecol. 2012;50:367-70.

6. Emerson SU, Tsarev SA, Govindarajan S, Shapiro M, Purcell RH. A simian strain of hepatitis A virus, AGM-27, functions as an 
attenuated vaccine for chimpanzees. J Infect Dis. 1996;173:592-7. http://dx.doi.org/10.1093/infdis/173.3.592

7. Drexler JF, Corman VM, Lukashev AN, Brand JMA, van den Gmyl AP,

Brünink S, et al. Evolutionary origins of hepatitis A virus in small mammals. Proc Natl Acad Sci U S A. 2015;112:15190-5. http://dx.doi.org/10.1073/pnas.1516992112

8. Drewe JA, O'Riain MJ, Beamish E, Currie H, Parsons S. Survey of infections transmissible between baboons and humans, Cape Town, South Africa. Emerg Infect Dis. 2012;18:298-301. http://dx.doi.org/10.3201/eid1802.111309

9. Goldberg TL, Gillespie TR, Rwego IB, Estoff EL, Chapman CA. Forest fragmentation as cause of bacterial transmission among nonhuman primates, humans, and livestock, Uganda. Emerg Infect Dis. 2008;14:1375-82. http://dx.doi.org/10.3201/eid1409.071196

10. Naughton-Treves L. Predicting patterns of crop damage by wildlife around Kibale National Park, Uganda. Conserv Biol. 1998; 12:156-68. http://dx.doi.org/10.1046/j.1523-1739.1998.96346.x

Address for correspondence: Tony L. Goldberg, Department of

Pathobiological Sciences, University of Wisconsin-Madison, 1656 Linden Dr, Madison, WI 53706, USA; email: tgoldberg@vetmed.wisc.edu

\section{Porcine Bocavirus Infection Associated with Encephalomyelitis in a Pig, Germany ${ }^{1}$}

\section{Vanessa M. Pfankuche, Rogier Bodewes, Kerstin Hahn, Christina Puff, Andreas Beineke, André Habierski, Albert D.M.E. Osterhaus, Wolfgang Baumgärtner}

Author affiliations: University of Veterinary Medicine, Hannover, Germany (V.M. Pfankuche, K. Hahn, C. Puff, A. Beineke,

A. Habierski, A.D.M.E. Osterhaus, W. Baumgärtner); Center for Systems Neuroscience, Hannover (V.M. Pfankuche, K. Hahn,

A. Beineke, W. Baumgärtner); The Erasmus University Medical Center, Rotterdam, the Netherlands (R. Bodewes); Utrecht University, Utrecht, the Netherlands (R. Bodewes)

DOI: http://dx.doi.org/10.3201/eid2207.152049

To the Editor: In 2013, a 6-week-old female piglet kept in a flatdeck cage had coughing, growth retardation, and diarrhea and was taken to a local veterinarian in Hannover, Germany; the piglet was euthanized. After necropsy at the University of Veterinary Medicine in Hannover, histologic investigation found interstitial pneumonia; a mild, multifocal, lymphohistiocytic panencephalitis that affected the cerebrum and cerebellum, including brain stem and

${ }^{1}$ Preliminary results from this study were presented at the 3rd International One Health Congress, March 15-18, 2015, Amsterdam, the Netherlands; and at the Conference of the German Veterinary Medical Association, March 8-10, 2015, Fulda, Germany. medulla oblongata; and a mild, multifocal, lymphohistiocytic panmyelitis. Results from screening for typical neurotropic viruses (classical swine fever virus, suid herpesvirus 1 , rabies virus, teschovirus, porcine enterovirus 8,9 , and 10) were negative; Mycoplasma hyorhinis was detected by multiplex PCR (Institute of Virology, University of Veterinary Medicine Hannover) within the lung and pulmonary lymph nodes. Cerebral tissue from the pig was processed for viral metagenomics by random RNA and DNA virus screening and next-generation sequencing (NGS) with the 454 sequencing platform (GS Junior; Roche, Basel, Switzerland), as described (1), and 21,359 reads were obtained. Analysis by using blastn and blastx (2) showed 10 reads had $\geq 97 \%$ nt identity with porcine bocavirus ( $\mathrm{PBoV}$ ) KU14. No other viral sequences were detected.

By using primers based on sequence data of the $\mathrm{PBoV}$, partially overlapping PCR amplicons were obtained to confirm and extend the NGS data of the isolate, which was named PBoV S1142/13 (1; GenBank accession no. KU311698). A total of 2,176 nt of PBoV S1142/13 were obtained, consisting of the partial nucleoprotein (NP) 1 and the nearly complete viral protein (VP) 1 gene. By using MAFFT version 7 (http://mafft.cbrc.jp/alignment/server/), we aligned the nearly complete VP1 gene of PBoV S1142/13 with various closely related members of the genus Bocaparvovirus and built a maximum-likelihood tree by using the general time reversible plus invariable sites plus gamma distribution method, as determined by jModelTest 2.0 (3) and default parameters in MEGA6.06 (4). Results confirmed that PBoV S1142/13 was most closely related to PBoV KU14 (Figure, panel A). The partial genome of PBoV S1142/13 differed at 8 nt positions from PBoV KU14, resulting in $99.6 \%$ nt identity. Of these nucleotide differences, 4 resulted in an amino acid difference, including position 2733 ( $\mathrm{T} \rightarrow \mathrm{C}$ on the basis of $\mathrm{PBoV}$ KU14 as a reference genome), which is part of the NP1 stopcodon of PBoV KU14. These results indicate that the stopcodon was located $39 \mathrm{nt}$ farther downstream than for PBoV KU14. The other 3 aa differences were present in the VP1 protein; each of these differences was within the same group of amino acids as those detected in PBoV KU14.

For further substantiation of a potential cause-effect relationship of histologic (Figure, panel B) and NGS results, we performed fluorescent in situ hybridization (FISH) on formalin-fixed, paraffin-embedded central nervous system (CNS) sections of the diseased animal and of a control pig with no CNS lesions. We used an RNA probe specific for the obtained NP1 and VP1 sequences covering 1,153 nt (Affymetrix, Santa Clara, CA, USA) according to the manufacturer's protocol, with minor variations (ViewRNA ISH Tissue 1-Plex Assay Kit and ViewRNA Chromogenic Signal Amplification Kit, Affymetrix). A probe specific for porcine ubiquitin (Sus scrofa ubiquitin 